\title{
Exfoliative Erythroderma
}

\author{
Višnja Milavec-Puretić ${ }^{\text {, Zdenka Zorić }}$, Martina Zidanić ${ }^{3}$, Ada Drčelić 4 , \\ Gordana Štajminger ${ }^{5}$
}

'University Department of Dermatology and Venereology, Zagreb University Hospital Center and School of Medicine, Zagreb; 'Department of Dermatology and Venereology, Zagreb Istok Polyclinic, Zagreb; ${ }^{3}$ Medical Center of the Sisak-Moslavina County, Sisak; ${ }^{4}$ Cand. med., School of Medicine, University of Zagreb; ${ }^{5}$ Clinic for Internal Medicine "Dr. Gordana Štajminger", Opatička 8, Zagreb, Croatia

\author{
Corresponding author: \\ Prof. Višnja Milavec-Puretić, MD, PhD \\ University Department of Dermatology \\ and Venereology \\ Zagreb University Hospital Center \\ and School of Medicine \\ Šalata 4 \\ HR-10000 Zagreb \\ Croatia \\ zdenkazoric@net.hr
}

Received: Janurary 8, 2007.

Accepted: February 20, 2007.

\begin{abstract}
SUMMARY Exfoliative erythroderma refers to the skin that is diffusely red and inflamed with varying degrees and types of scaling. There are many causes of erythroderma, but the most common are exacerbations of an underlying skin disease, drug reactions and underlying malignancies. Erythroderma is a rare, potentially serious skin condition. Protein loss in the form of desquamation and exudation is significant, resulting in hypoproteinemia. Usually more than one skin biopsy should be done. Biopsy analysis is important to rule out cutaneous T-cell lymphoma. Patients should be carefully evaluated for underlying disease. Erythroderma can represent a serious medical threat to the patient, and may require hospitalization. Various forms of exfoliative erythroderma are presented, considering the etiopathogenesis, physical findings, differential diagnosis and treatment.
\end{abstract}

KEY WORDS: exfoliative erythroderma, exfoliative dermatitis, Sézary syndrome, cutaneous T-cell lymphoma

\section{INTRODUCTION}

Erythroderma refers to the skin that is diffusely red and inflamed with varying degrees and types of scaling (1). There are many causes of erythroderma, but the most common are exacerbations of an underlying skin disease, drug reactions and malignancies, primarily mycosis fungoides (MF). Usually more than $90 \%$ of the skin is involved, but residual islands of normal skin may be of great importance in clinical diagnosis. For example, pityriasis rubra pilaris (PRP) and MF are characterized by such spared areas. The scales may vary greatly, coming off in sheets in acute drug induced erythroderma, but being smaller or finer in psoriasis or PRP. Pruritus is common and often unbearable (1).
Erythroderma can be classified into primary and secondary types. In primary erythroderma, skin changes arise on the previously normal skin, usually as part of malignant lymphoma or of drug reactions. In secondary erythroderma, an underlying skin disease is spreading and it involves the entire skin (e.g., psoriasis, allergic contact dermatitis, PRP or lichen ruber planus) (2).

\section{EPIDEMIOLOGY}

Erythroderma is a rare, yet easily recognized, potentially serious skin condition. Its reported incidence varies widely, from 1 to 71 per 100,000 dermatologic outpatients (3-5). Studies in large patient series focused on male to female ratio, 
mean age and underlying diseases (3-11). Men are more commonly affected (male to female ratio of approximately $2: 1$ to $4: 1$ ) and the mean age is between 40 and 60 years (12). Among 746 patients, the most common underlying causes of erythroderma were dermatitis $(24 \%)$, psoriasis (20\%), drug reactions (19\%) and cutaneous T-cell lymphoma (CTCL) accounting for $8 \%$ of cases (12).

In $25 \%-39 \%$ of patients, the cause of erythroderma remains unknown (idiopathic) and some of these patients eventually develop CTCL (13). This group consists primarily of elderly men with a chronic course of relapsing pruritic erythroderma in association with dermatopathic lymphadenopathy and extensive palmoplantar keratoderma (13).

\section{PATHOGENESIS}

Erythroderma has profound effects on the entire body. The widespread inflammatory response, increased blood flow and marked desquamation all take their toll. Vasodilatation and increased blood flow lead to chills and impaired temperature control. Hypothermia is a possible complication. Increased evaporation is possible by increased blood flow and damaged epidermal barriers, leading to dehydration and fluid problems. Protein loss in the form of desquamation and exudation is significant, resulting in hypoproteinemia. The daily loss of scales increases from 500-1000 mg to $20-30 \mathrm{~g}(1,14)$. Typically, there is hypoalbuminemia with a relative increase in immunoglobulins, especially $\gamma$-globulins. Both hair and nails are influenced by the increased demands, telogen effluvium and transverse nail bands are expected. Cardiovascular, renal and hepatic complications are common (1). Generalized lymphadenopathy is found very often (15).

\section{SPECIFIC FINDINGS OF THE UNDERLYING DISEASE}

\section{Psorasis}

Psoriatic erythroderma (Fig. 1) is preceded by typical psoriatic plaques. Its onset is most often the result of a sudden withdrawal of potent topical or oral corticosteroids, methotrexate, phototoxicity or systemic infection. Nail changes such as oil drops changes, onycholysis, or nail pits, may still be visible and provide valuable clues to the diagnosis of psoriatic erythroderma. According to Tomasini et al., in a group of patients with a discharge diagno-

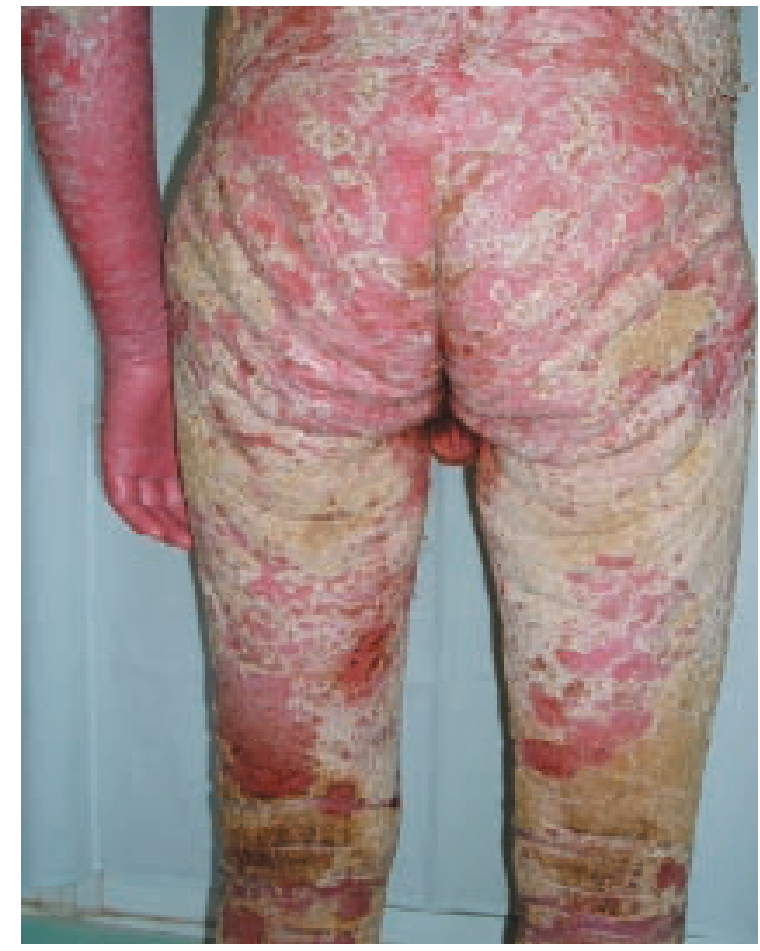

Figure 1. Psoriatic erythroderma.

sis of psoriatic erythroderma, the histopathologic changes were specific for psoriasis in 40 (88\%) cases (16).

\section{Atopic dermatitis}

Atopic erythroderma (Fig. 2) is most frequently found in patients with a history of moderate to severe atopic dermatitis. The pruritus is intense. Increased serum $\lg E$ and eosinophilia may be accompanied with other signs and symptoms of atopy. A constant histologic finding in atopic erythroderma is mild to moderate spongiosis, which is sometimes located in the follicular infundibulum. Almost always, acanthosis and parakeratosis are additional histologic features (12).

\section{Drug reactions}

The list of drugs that cause exfoliative dermatitis is large and continuously growing. Histologically, changes vary considerably. More than 60 drugs have been implicated in the causation of erythroderma. Among the most commonly implicated are pyrazolone derivatives, carbamazepine, hydantion derivatives, cimetidine, lithium salts, and gold and gold salts (1).

\section{Netherton's syndrome}

Netherton's syndrome manifests as an erythroderma in neonates. It is associated with trichor- 


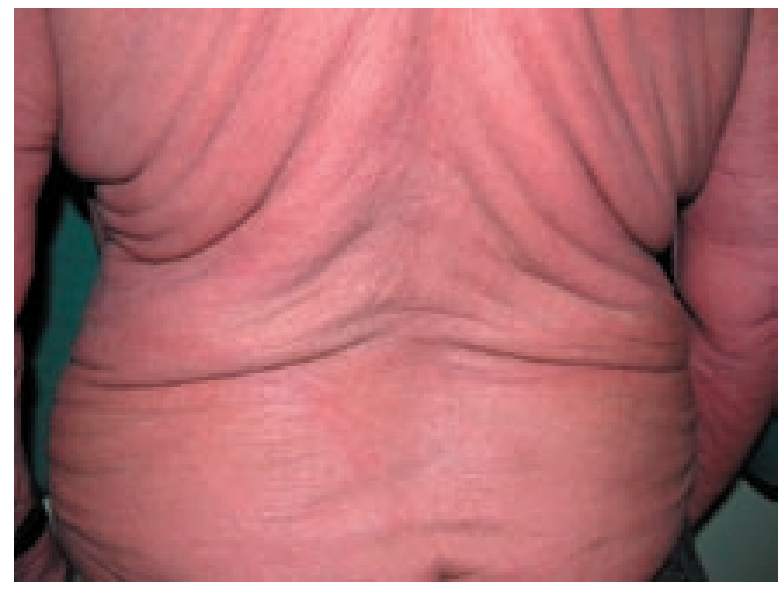

Figure 2. Atopic erythroderma

rexis invaginata ("bamboo hair"), atopic dermatitis and an immune defect that can result in life threatening infections (17).

\section{Cutaneous T-cell lymphoma}

Erythroderma due to CTCL is subdivided into Sézary syndrome and erythrodermic mycosis fungoides. Sézary syndrome (Fig. 3) is defined by the triad of symptoms: erythroderma, circulating malignant $\mathrm{T}$ lymphocytes, and generalized lymphadenopathy. Additional clinical features include painful and fissured keratoderma, diffuse alopecia and leonine facies. The skin may be strongly infiltrated and severe pruritus is common. The manifestations of erythrodermic mycosis fungoides are clinically identical to Sézary syndrome, but leukemic Sézary cells are absent. The histologic picture of typical erythrodermic CTCL consists of a band-like infiltrate in the papillary dermis containing small to medium sized mononuclear cells with hyperchromatic, cerebriform nuclei as well as a variable number of inflammatory cells (18).

\section{Paraneoplastic erythroderma}

Erythroderma can also be a paraneoplastic marker for a wide range of hematologic malignancies, and rarely even for other solid tumors. In such cases, the onset is more rapid and there is no history of precursor lesions. Histologic examination of the lymph nodes or other tissue is crucial because the skin changes are rarely caused by infiltrating tumor cells (12).

\section{Pityriasis rubra pilaris}

Erythrodermic PRP can be observed in children and adults. Usually the lesions have a salmon or orange-red color. The presence of perifollicular keratotic plugs on the knees, elbows and dorsal side of the hands, as well as nappes claires (islands of uninvolved skin) within the erythroderma, is highly suggestive of PRP. The characteristic histologic finding in PRP is orthokeratosis foci alternating with parakeratosis in both vertical and horizontal directions (12).

\section{Omenn's syndrome}

Omenn's syndrome represents an autosomal recessive form of severe combined immunodeficiency and is characterized by leukocytosis with prominent eosinophilia and increased T/B cell ratio, hypogammaglobulinemia and elevated $\lg \mathrm{E}$ levels. Cutaneous findings include exfoliative erythroderma with diffuse alopecia $(19,20)$.

\section{DIAGNOSTIC APPROACH}

Clinical recognition of the erythroderma is easy, but the diagnosis of the underlying cause may be very difficult. The issue is deciding which triggered or caused the problem, primary or secondary erythroderma. The existence of previous skin disease and how it was treated are crucial. The age of the patient also play a role. One must search carefully for subtle signs of an underlying disease. Many patients have lymphadenopathy which, while usually reactive or dermatopathic, may reflect an un-

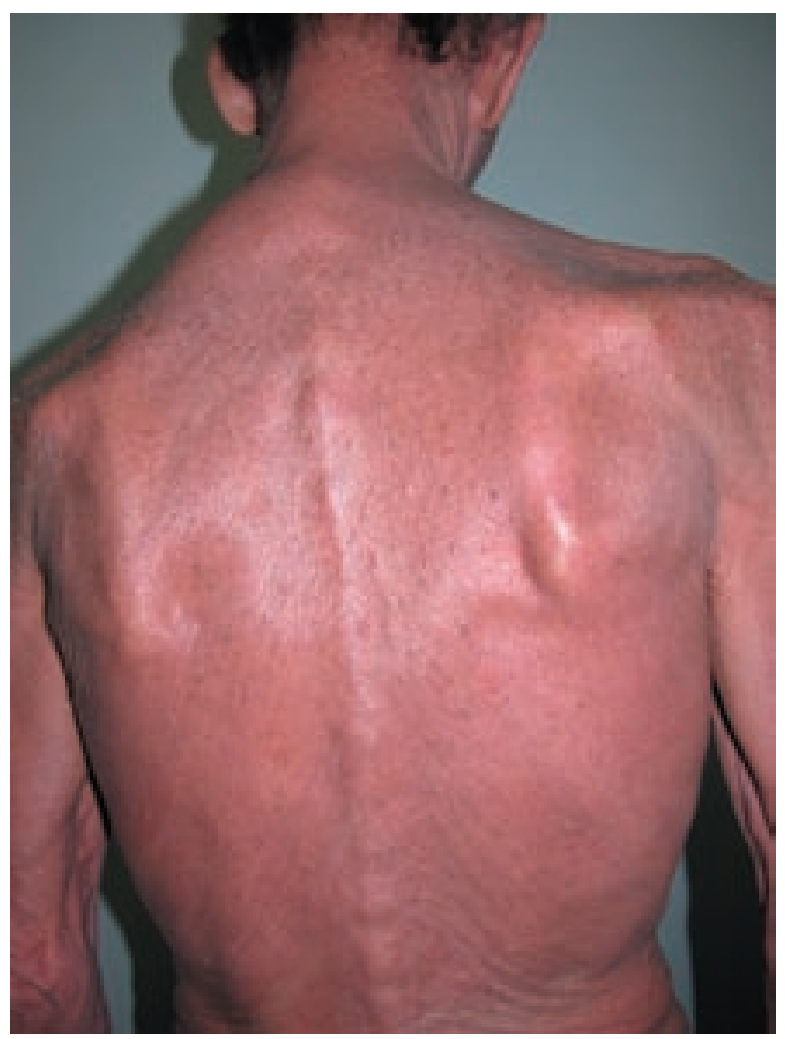

Figure 3. Sézary syndrome 
derlying lymphoma. If the diagnosis is unclear, a lymph node biopsy should be considered.

Usually more than one skin biopsy should be done. Multiple biopsies are usually but not invariably helpful because they may not show any distinctive histologic features. The biopsy is important to rule out CTCL. The patients should be carefully evaluated for underlying disease. Lymph node biopsy is advisable if lymphoma is suspected. Useful approaches include chest x-ray, computerized tomography of the abdomen, pelvis and thorax, routine blood evaluation, iron and folic acid levels, immunoelectrophoresis, and bone marrow examination (1).

\section{TREATMENT}

Erythroderma can pose a serious medical threat to the patient and may require hospitalization. The patients are more comfortable if they are in warm, humid environment. The initial management consists of nutritional assessment, correction of fluid and electrolyte imbalances, prevention of hypothermia, and treatment of secondary infections. Sedating oral antihistamines may ease the often severe pruritus. Systemic corticosteroids may be necessary in idiopathic erythroderma and drug reactions. Topical therapy includes open wet dressings and bland emollients or low-potency corticosteroid ointments. High-potency topical corticosteroids should be avoided due to increased transcutaneous absorption (21).

\section{PROGNOSIS}

Drug induced cases have the best prognosis, as they have rapid improvement $(4,10)$. Secondary erythroderma to underlying skin diseases tends to improve over a few weeks, and as many as twothirds of patients enter remission (22). Exfoliative dermatitis secondary to CTCL and internal malignancies tends to be more persistent (23).

\section{References}

1. Braun-Falco O, Plewig G, Wolf HH, Burgdorf WHC. Erithemato-papulo-squamous disease. In: Braun-Falco O, Plewig G, Wolf HH, Burgdorf WHC, editors. Deramatology. $2^{\text {nd }}$ completely revised edition. Berlin: Springer; 2000. p. 620-3.

2. Pašić A, Lipozenčić J. Eritrodermije. In: Lipozenčić J editor. Dermatovenerologija. Zagreb: Medicinska naklada; 2004. p. 211-3.
3. Seghal VN, Srivastava G. Exfoliative dermatitis: a prospective study of 80 patients. Dermatologica 1986;173:278-84.

4. Hasan T, Jasen CT. Erythroderma: a follow-up of fifty cases. J Am Acad Dermatol 1983;8:83640.

5. Wong KS, Wong SN, Tham SN, Giam YC. Generalised exfoliative dermatitis: a clinical study of 108 patients. Ann Acad Med Singapore 1988;17:520-3.

6. Abrahams I, McCarthy JT, Sanders SS. 101 cases of exfoliative dermatitis. Arch Dermatol 1963;87:96-101.

7. Botella-Estrada R, Sanmartin O, Oliver V, Febrer I, Aliaga A. Erythroderma. A clinicopathological study of 56 cases. Arch Dermatol 1994;130:1503-7.

8. Sigurdsson V, Toonstra J, Hezemans-Boer M, van Vloten WA. Erythroderma. A clinical and follow-up study of 102 patients, with special emphasis on survival. J Am Acad Dermatol 1996;35:53-7.

9. Pal S, Haroon TS. Erythroderma: a clinicoetiologic study of 90 cases. Int J Dermatol 1998;37:104-7.

10. King LE Jr, Dufresne Rg Jr, Lovett GL, Rosin MA. Erythroderma: review of 82 cases. South Med J 1986;79:1210-5.

11. Nicolis GD, Helwig EB. Exfoliative dermatitis. A clinicopathologic study of 135 cases. Arch Dermatol 1973;108:788-97.

12. Sterry W, Muche M. Erythroderma. In: Bolognia JL, Jorizzo JL, Rapini RP, editors. Dermatology. Edinburgh: Mosby; 2003. p. 165-74.

13. Thestrup-Pederson K, Halkier-Sorensen L, Sogaard $\mathrm{H}$, Zachariae $\mathrm{H}$. The red man syndrome. Exfoliative dermatitis of unknown etiology: a description and follow-up of 38 patients. J Am Acad Dermatol 1988;18:1307-12.

14. Kanthraj GR, Srinivas CR, Devi PU, Ganasoundari A, Shenoi SD, Deshmukh RP, et al. Quantitative estimation and recommendations for supplementation of protein lost through scaling in exfoliative dermatitis. Int J Dermatol 1999;38:91-5.

15. Dobrić I, Pašić A. Maligni limfomi i pseudolimfomi kože te promjene kože kod leukemija. In: Dobrić I, editor. Dermatovenerologija. Third revised edition. Zagreb: Grafoplast; 2005: p. 417-28.

16. Tomasini C, Aloi F, Solaroli C, Pippione M. Psoriatic erythroderma: a histopathologic study 
of forty five patients. Dermatology 1997;194: 102-6.

17. Brodin MB, Porter PS. Netherton's syndrome. Cutis 1980;26:185-8, 191.

18. Smoller BR, Bishop K, Glusac E, Kim YH, Hendrickson M. Reassessment of histologic parameters in the diagnosis of mycosis fungoides. Am J Surg Pathol 1995;19:1423-30.

19. Omenn GS. Familiar reticuloendotheliosis with eosinophilia. N Engl J Med 1965;273:427-32.

20. Pupo RA, Tyring SK, Raimer SS, Wirt DP, Brooks EG, Goldblum RM. Omenn's syndrome and related combined immunodeficiency syndromes: diagnostic considerations in infants with persistent erythroderma and failure to thrive. J Am Acad Dermatol 1991;25:442-6.

21. Rothe MJ, Bialy TL, Grant-Kels JM. Erythroderma. Dermatol Clin 2000;18:405-15.

22. Boyd AS, Menter A. Erythrodermic psoriasis. Precipitating factors, course and prognosis in 50 patients. J Am Acad Dermatol 1989;21:98591.

23. Kim YH, Bishop K, Varghese A, Hoppe RT. Prognostic factors in erythrodermic mycosis fungoides and the Sezary syndrome. Arch Dermatol 1995;131:1003-8.

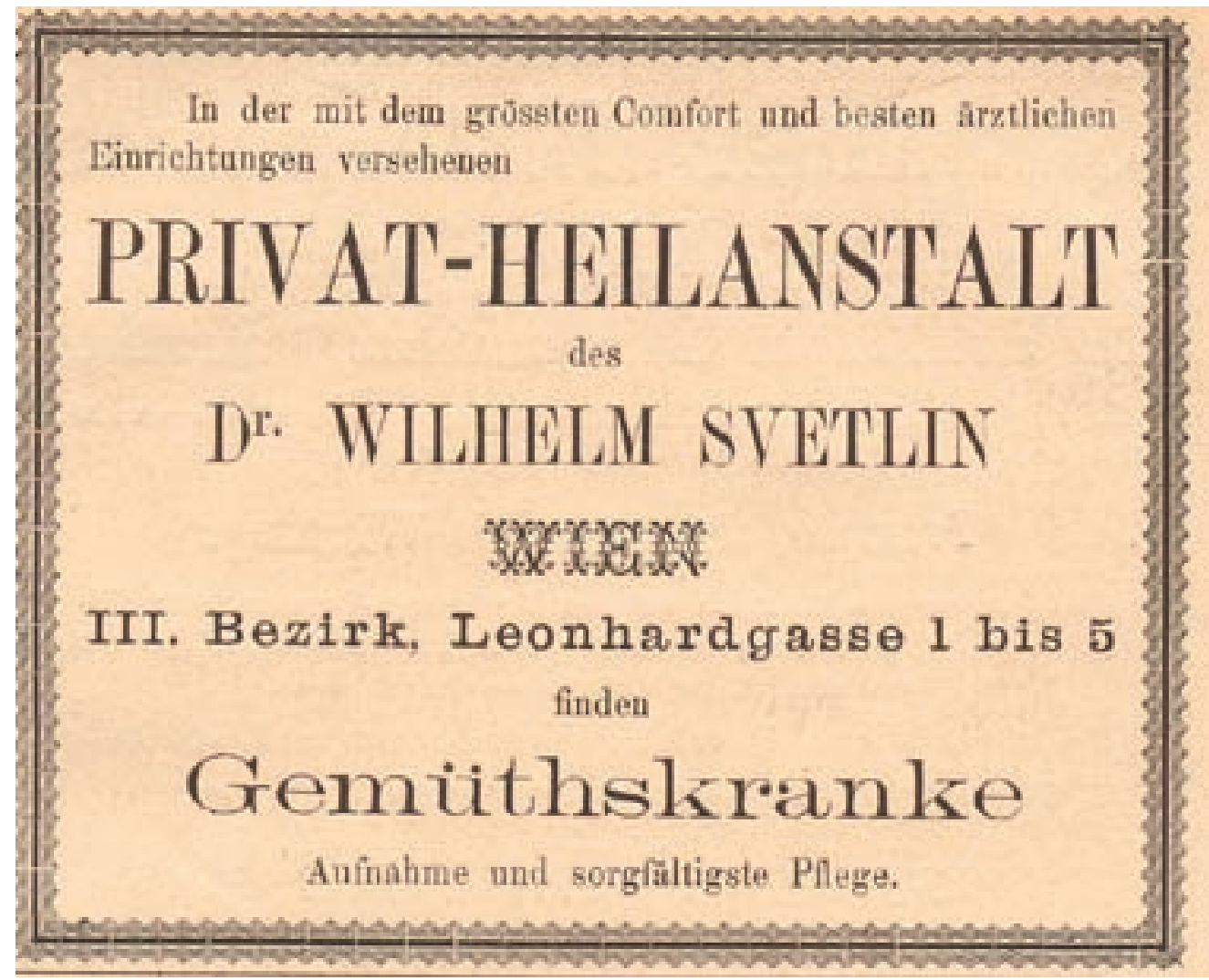

Private health resort Dr. Wilhelm Svetlin in Vienna; year 1931.

(from the collection of Mr. Zlatko Puntijar) 